\title{
Comparison of plasma and intra-articular gentamicin levels after intravenous administration in healthy horses
}

\author{
Marília Alves Ferreira, Mayra Lissoni Aguiar, Renan Grigoletto, Danielle Passarelli, \\ Julia de Assis Arantes, Gustavo Morandini Reginato, Pedro Henrique Salles Brito \\ Thiago Jonatha Fernandes da Silva, Renata Gebara Sampaio Dória
}

University of Sao Paulo (USP), Faculty of Animal Science and Food Engineering (FZEA), Pirassununga, São Paulo, Brazil

Received June 10, 2019

Accepted June 22, 2020

\begin{abstract}
Septic arthritis is considered one of the most severe disorders that affect horses' joints. Therapy is intended to eliminate the microorganisms that cause this infection. The intravenous administration of antibiotics is an easily performed technique, but there is no guarantee that the antibiotics will reach the joint milieu at high concentrations and remain elevated for a certain period of time. This study aimed to determine and compare the levels of gentamicin in the plasma and synovial fluid of healthy horses after intravenous administration for seven days. Five horses received $6.6 \mathrm{mg} / \mathrm{kg}$ intravenous gentamicin every $24 \mathrm{~h}$ for seven consecutive days. Blood and synovial fluid samples were collected from the right metacarpal-phalangeal joint before the start of the treatment (T0) and after $6 \mathrm{~h}$ (T6), $12 \mathrm{~h} \mathrm{(T12),} \mathrm{and} \mathrm{every} 24 \mathrm{~h}$ during antibiotic therapy for seven days (D1 to D7). The levels of gentamicin in serum and synovial fluid were quantified by Enzyme-Linked Immunosorbent Assay (ELISA). The intravenous administration of $6.6 \mathrm{mg} / \mathrm{kg}$ of gentamicin, in horses, after a period of $24 \mathrm{~h}$, promotes synovial fluid concentrations below the MIC of the drug, in spite of reaching high plasma concentrations of gentamicin, daily mean serum concentration which was 29 -fold higher than the minimum inhibitory concentration (MIC) of the drug. The intravenous administration every $24 \mathrm{~h}$ during seven consecutive days did not cause systemic side effects, such as hepatic or renal injury.
\end{abstract}

Septic arthritis, ELISA, minimal inhibitory concentration

The joints and their adjacent tissues, like cartilage and synovial membrane, are predisposed sites for bacterial infection, due to reduced vascularization and reduced oxygen, leading to septic arthritis (Meijer et al. 2000; Taylor et al. 2010). In horses, appropriate treatment should be initiated as soon as possible, to avoid the degeneration of the articulation and synovial structures (Nix et al. 1991; Morton 2005). Traditionally, systemic antibiotic therapy, joint lavage, and intra-articular administration of antibiotics are used for the treatment of septic arthritis, given that appropriate concentrations of antibiotics in the infected joint are important, so that the infection can be eliminated (Doria et al. 2010; Motta et al. 2017).

The aminoglycosides amikacin and gentamicin are effective antibiotics against Gram negative bacteria, used to treat severe conditions (Firth 1983; Nix et al. 1991; Durham 2018). In horses, the administration of gentamicin is recommended at a dose of $6.6 \mathrm{mg} / \mathrm{kg}$ intravenously with a volume of distribution of $0.18-0.31 / \mathrm{kg}$; clearance of $1.1-2.2 \mathrm{ml} / \mathrm{min} / \mathrm{kg}$; and half-life of $1.5-4 \mathrm{~h}$, as pharmacokinetic characteristics (Spinosa 2006). Gentamicin is effective against more than $80 \%$ of bacteria isolated from musculoskeletal diseases of horses, and is active in the synovial fluid (Snyder et al. 1987). The minimum inhibitory concentration (MIC) of gentamicin in horses is $2 \mu \mathrm{g} / \mathrm{ml}$ (Moore et al. 1987; Lloyd et al.1988; Skopnik et al. 1992).

The therapeutic success of aminoglycoside antibiotics is associated with the maximum concentration of the drug $\left(\mathrm{C}_{\max }\right)$ that is 8-10 fold higher than the MIC (Moore et al. 1987;

Address for correspondence:

Marília Alves Ferreira

Campus Fernando Costa - USP

Avenue Duque de Caxias Norte, 225

13635-900, Pirassununga, São Paulo, Brazil

Phone: +55 (19) 3565-4200

E-mail: marilia.alves.ferreira@usp.br

http://actavet.vfu.cz/ 
Lloyd et al. 1988; Skopnik et al. 1992; Morton 2005). The concentration or dosedependent bactericidal activity of gentamicin is related to its peak serum levels (i.e., the higher the concentration of the drug, the faster and higher the bactericidal effect), with important residual bacteriostatic activity, which reflects the maintenance of bacterial growth suppression even when serum concentrations of the drug are lower than the MIC (Spinosa 2006). Recent studies have reported high bacterial resistance in the synovial fluid of horses with septic arthritis, involving the drugs penicillin, enrofloxacin, and amikacin. Bacterial resistance to an antibiotic drug is mainly due to repeated exposure to below adequate antimicrobial concentrations (Motta et al. 2017; Durha 2018). Thus, it is hypothesized that the intravenous administration of an antibiotic for the treatment of joint infections can be responsible for bacterial resistance to the drug and persistence of the disease.

Although the intravenous administration of antibiotic drugs is a relatively easy technique to perform, there is no guarantee that antibiotics will reach the joint environment at sufficiently high concentrations and remain elevated for a certain period of time. Numerous factors alter the intra-articular concentration of an intravenous drug, including the low protein content of the synovial fluid, which does not favour passive diffusion; the concentration of a drug in the synovial fluid is dependent on active transport (Nix et al. 1991). In addition, factors such as local $\mathrm{pH}$, blood flow, and presence of inflammatory and/ or infectious processes may interfere with the transport of antibiotics to the synovial fluid when administered systemically (Meijer et al. 2000; Morton 2005; Schnabel 2012). In order to verify whether intravenous administration of gentamicin should be performed to treat arthritis in horses, the present study aimed to determine and compare the concentration of gentamicin in plasma and synovial fluid of healthy horses during seven days of daily intravenous administration and concomitantly evaluate the systemic adverse effects of continued use of the drug.

\section{Materials and Methods}

Five adult horses were used, four males and one mare, of undefined breed, considered healthy after clinical and laboratory examinations, with a mean body weight of $300 \pm 50 \mathrm{~kg}$. During the pre-experimental phase, animals were housed in paddocks, provided hay, mineral supplementation, and water ad libitum for adaptation and conditioning to the routine of the experiment. Before the beginning of the experiment all animals were subjected to haematological and biochemical (liver and kidney function) evaluation and cytological analysis of the synovial fluid. Only horses with indices within the physiological normal range were included in the study.

Each horse received $6.6 \mathrm{mg} / \mathrm{kg}$ gentamicin (Virbac, Brazil), in the right jugular vein, in a standardized schedule, every $24 \mathrm{~h}$ for seven consecutive days. The volume of gentamicin calculated for the weight of each animal was diluted in $200 \mathrm{ml}$ of Ringer's lactate (Fresenius Kabi Brasil Ltda, Brazil) and administered with the aid of a $14 \mathrm{G}$ catheter (Nipro Medical Ltda, Brazil).

Samples of blood and synovial fluid from the left metacarpophalangeal joint were collected before the start of the experiment (T0) and 6 (T6), 12 (T12), 24 (D1), 48 (D2), 72 (D3), 96 (D3), 120 (D4), 144 (D5), 168 (D6) and 192 (D7) $\mathrm{h}$ after the first gentamicin intravenous administration. The samples were collected just before the daily antibiotic administration. Blood was collected in dry tubes following puncture of the left jugular vein (Labor Import, Brazil) to obtain serum samples. Synovial fluid was obtained after clipping the metacarpophalangeal region of the left thoracic limb of each animal and antiseptic treatment with a chlorhexidine antiseptic solution, followed by alcohol. With a sterile glove (Descarpack, Brazil), a $30 \times 08$ disposable needle (Labor Import, Brazil) was introduced into the palmar recess of the metacarpal-phalangeal joint, between the third metacarpal bone and the dorsal border of the lateral branch of the suspensory ligament. After access to the joint, a $5 \mathrm{ml}$ disposable syringe with a slip tip (Descarpack, Brazil) was attached to the needle cannula (Labor Import, Brazil), and $1 \mathrm{ml}$ synovial fluid was aspirated. After harvesting the synovial fluid, a dressing and a compression bandage were placed on the region to avoid joint infection.

Samples of blood serum and synovial fluid were stored in sterile Eppendorf tubes (Eppendorf AG, Brazil), at $-80^{\circ} \mathrm{C}\left(-112^{\circ} \mathrm{F}\right)$, for the assessment of the concentration of gentamicin, through enzyme-linked immunosorbent assay (ELISA; kit "Gentamicin ELISA").

An aliquot of each serum sample was sent to the Clinical Analysis Laboratory for serum biochemistry to evaluate the liver function (aspartate amino transferase, alkaline phosphatase, gamma glutamyl transferase, total protein, albumin, and globulin) and renal function (urea and creatinine), carried out by commercial kits (Labtest ${ }^{\mathbb{B}}$, Brazil), in automated equipment BS120 (Mindray ${ }^{\mathbb{R}}$, China). 
The data obtained in the experimental phase were analysed as repeated measurements over time on the PROC MIXED of SAS 9.0 to determine if the effect of the treatment time, and the interaction between time and treatment, were significant. The means were compared by Tukey test at a significance level of $5 \%$.

\section{Results}

The mean serum gentamicin concentrations at some experimental time points were significantly different. An elevation of serum concentration of gentamicin was observed at T6 and T12, followed by a reduction, which remained stable from D1 to D4. From D5 to D7, serum concentrations were again elevated, and stabilized at a level similar to T12. It should be emphasized that these mean serum concentrations were 29-fold higher than the MIC of gentamicin for horses (Table 1). No serum biochemical abnormalities were observed during the experimental period for either experimental group with regards to liver or kidney function (Table 2).

Table 1. Mean and standard deviation of the level of gentamicin $(\mu \mathrm{g} / \mathrm{ml})$ in the serum and synovial fluid, over time, in horses receiving intravenously administered gentamicin at $6.6 \mathrm{mg} / \mathrm{kg}$, every $24 \mathrm{~h}$ for seven days.

\begin{tabular}{|c|c|c|}
\hline Time (hours) & Serum concentration $(\mu \mathrm{g} / \mathrm{ml}) \pm \mathrm{SD}$ & Synovial fluid concentration $(\mu \mathrm{g} / \mathrm{ml}) \pm \mathrm{SD}$ \\
\hline T0 (basal) & $0 \mathrm{~d}$ & $0 \mathrm{~d}$ \\
\hline T6 (6 h) & $154.92 \pm 29.20^{\mathrm{a}}$ & $1.33 \pm 0.13^{\mathrm{a}}$ \\
\hline T12 (12 h) & $131.25 \pm 52.20^{\mathrm{ab}}$ & $1.20 \pm 0.13^{\mathrm{ab}}$ \\
\hline D1 (24 h) & $58.63 \pm 32.04^{\mathrm{cd}}$ & $0.84 \pm 0.15^{\mathrm{c}}$ \\
\hline D2 (48 h) & $62.14 \pm 37.07^{\mathrm{cd}}$ & $0.81 \pm 0.14^{\mathrm{c}}$ \\
\hline D3 (72 h) & $66.13 \pm 38.39^{c}$ & $0.90 \pm 0.14^{\mathrm{bc}}$ \\
\hline D4 (96 h) & $67.35 \pm 42.55^{\mathrm{c}}$ & $0.92 \pm 0.20^{\mathrm{bc}}$ \\
\hline D5 (120 h) & $88.90 \pm 40.90^{\mathrm{bc}}$ & $0.94 \pm 0.14^{\mathrm{bc}}$ \\
\hline D6 (144 h) & $84.30 \pm 21.25^{\mathrm{bc}}$ & $1.02 \pm 0.14^{\mathrm{abc}}$ \\
\hline D7 (168 h) & $89.11 \pm 34.41^{\mathrm{bc}}$ & $0.99 \pm 0.28^{\mathrm{bc}}$ \\
\hline
\end{tabular}

Different superscripts mean a significant difference between times $(P \leq 0.05)$. SD - standard deviation. Reliability of the standard curve of the gentamicin ELISA in serum: 95\%. Reliability of the standard curve of the "ELISA Gentamicin" assay in synovial liquid: $92 \%$.

The mean concentration of gentamicin in the synovial fluid was significantly different from that in serum at all experimental time points (Table 1). The highest concentrations in the synovial fluid were obtained in the first 6 and $12 \mathrm{~h}$. Afterwards, there was a reduction of intra-articular concentration of gentamicin at D1 and D2, which remained stable and similar to $\mathrm{T} 12$, from $\mathrm{D} 3$ to $\mathrm{D} 7$. In contrast to the serum, mean concentrations in the synovial fluid did not reach the MIC of gentamicin for horses at any of the experimental time points (Table 1).

The correlation coefficient between the concentration of gentamicin in the serum and the synovial fluid was 0.78 considered to be a good correlation for biological samples. Therefore, when serum levels of gentamicin increased or decreased during the experimental period after the applications of intravenous gentamicin, the levels of gentamicin in the synovial fluid also increased or decreased, culminating in a proportional relationship between the two.

\section{Discussion}

Treatment with intravenous gentamicin in horses is usually performed at a daily dose of $6.6 \mathrm{mg} / \mathrm{kg}$ for four consecutive days (Spinosa 2006). In this study, the intravenous administration of gentamicin at a dose recommended by the literature led to serum 


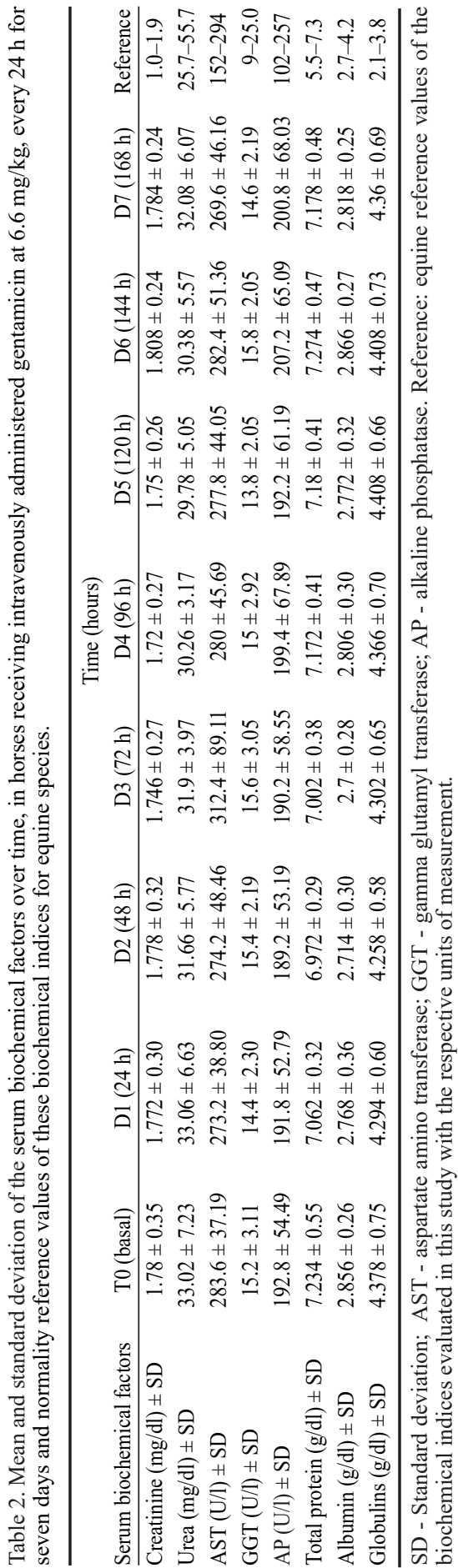

concentrations of the drug well above the MIC within $6 \mathrm{~h}$ after drug administration. Serum gentamicin concentration was maintained at a consistently high level above the MIC with the continued daily administration of the drug. Mean serum concentrations were from 77-fold (T6; $154.92 \pm 29.20 \mu \mathrm{g} / \mathrm{ml})$ to 29 -fold (D1; $58.63 \pm 32.04 \mu \mathrm{g} / \mathrm{ml}$ ) higher than the MIC of gentamicin for horses $(2 \mu \mathrm{g} / \mathrm{ml})$. Thus, this study demonstrates that gentamicin can be used in the equine species for the treatment of systemic infections responsive to the drug, as its continuous intravenous administration achieves and maintains serum concentrations above the MIC.

On the contrary, this study showed that the concentration of gentamicin in the synovial fluid of horses remained below the MIC of $2 \mu \mathrm{g} / \mathrm{ml}$ at all experimental time points, even after repeated daily administrations of gentamicin. Considering that in horses, a maximum concentration of at least 8 - to 10 -fold the MIC is desired to resolve joint infections (Moore et al. 1987; Lloyd et al. 1988; Skopnik et al. 1992; Morton 2005), treatment with intravenous gentamicin at a daily dose of $6.6 \mathrm{mg} / \mathrm{kg}$ for seven consecutive days is insufficient. Although the systemic administration of gentamicin is reported to result in concentrations above the MIC of the drug in healthy joints (Morton 2005; Schnabel 2012), the results of this study suggest that other routes of administration should be used in the clinic, such as regional perfusion, intravenous or intraosseous perfusion, or even intra-articular administration of the drug (Santschi et al. 1998; Butt et al. 2001; Scheuch et al. 2002; Mattson et al. 2004; Rubio-Martínez and Cruz 2006).

In this study, a peak serum concentration was attained, both in the serum and the synovial fluid, from 6 and $12 \mathrm{~h}$ after the initial intravenous administration of the drug, although the synovial concentration of gentamicin did not reach the MIC of the drug. This peak can be explained by the shorter time intervals in which the sampling was done, since the peak plasma concentration of gentamicin is a time-dependent variable of drug administration (Durham 2018). During this period, the serum concentration of gentamicin is higher as metabolism and excretion is only starting to occur. Since treatment with 
intravenous gentamicin in horses is recommended to be performed once every $24 \mathrm{~h}$, it is important to know the gentamicin concentration in the synovial fluid after this entire period, before the next drug re-administration. Lower mean values of gentamicin were determined $24 \mathrm{~h}$ after the intravenous administration of gentamicin, when metabolism and excretion have occurred to a greater degree. The mean synovial fluid concentration remained 116-fold (T6; synovial: $1.33 \pm 0.13 \mu \mathrm{g} / \mathrm{ml} \times$ serum: $154.92 \pm 29.20 \mu \mathrm{g} / \mathrm{ml}$ ) to 70 -fold (D1; synovial: $0.84 \pm 0.15 \mu \mathrm{g} / \mathrm{ml} \times$ serum: $58.63 \pm 32.04 \mu \mathrm{g} / \mathrm{ml})$ lower than in plasma, and did not reach the MIC at any experimental time point, even with daily re-administrations of the drug. It should be emphasized that in joint infections, local changes in the $\mathrm{pH}$, blood flow, and capillary obstruction by fibrin and debris can interfere with the transport of antibiotics, thereby restricting the appropriate local distribution of a drug after systemic administration (Schnabel 2012). In these situations, the synovial antibiotic concentration would be further decreased, thus lending additional support to the assertion that the treatment of joint infections with systemic antibiotics, such as gentamicin, is not feasible.

The serum biochemical evaluation of horses treated with intravenous administration of gentamicin at a dose of $6.6 \mathrm{mg} / \mathrm{kg}$ for seven consecutive days did not lead to significant changes in liver or kidney function, remaining within the normal physiological range for equine species at all experimental time points, according to Thrall (2015), as shown in Table 2. These data suggest that intravenous administration of gentamicin in healthy equines for seven consecutive days is safe and does not lead to hepatic or renal injury, although aminoglycosides are feared mainly for their nephrotoxic potential (Oliveira et al. 2006; Lopez-Novoa et al. 2011).

In conclusion, the intravenous administration of $6.6 \mathrm{mg} / \mathrm{kg}$ of gentamicin in horses after a period of $24 \mathrm{~h}$, promotes synovial fluid concentrations below the MIC of the drug, in spite of reaching high plasma concentrations of gentamicin. The intravenous administration every $24 \mathrm{~h}$ for seven consecutive days did not cause systemic side effects such as hepatic or renal injury.

\section{Acknowledgments}

The authors acknowledge the financial support from Fundação de Amparo à Pesquisa do Estado de São Paulo (Fapesp - process no. 2013/20662-8 and 2019/03193-0) and Conselho Nacional de Desenvolvimento Científico e Tecnológico (CNPq - process no. 449297/2014-4).

\section{References}

Butt TD, Bailey JV, Dowling PM, Fretz PB 2001: Comparison of 2 techniques for regional antibiotic delivery to the equine forelimb: intraosseous perfusion vs. intravenous perfusion. Can Vet J 42: 617-622

Dória RG, Freitas SH, Valadão CA 2010: Perfusão regional intravenosa dos membros de equinos - Revisão bibliográfica. Revista Brasileira de Medicina Equina 5: 14-20

Durham AE 2018: An evaluation of serum gentamicin concentrations and bacterial susceptibility to gentamicin in equine practice. J Vet Intern Med 32: 1194-1201

Firth E 1983: Current concepts of infectious polyarthritis in foals. Equine Vet J 15: 5-9

Lloyd KC, Stover SM, Pascoe JR, Baggot JD, Kurpershoek C, Hietala S 1988: Plasma and synovial fluid concentrations of gentamicin in horses after intra-articular administration of buffered and unbuffered gentamicin. Am J Vet Res_49: 644-649

Lopes-Novoa J, Quiros Y, Vicente L, Morales A, Lopez-Hernandez J 2011: New insights into the mechanism of aminoglycoside nephrotoxicity: an integrative point of view. Kidney Int 79: 33-45

Mattson S, Boure L, Pearce S, Hurtig M, Burger J, Black W 2004: Intraosseous gentamicin perfusion of the distal metacarpus in standing horses. Vet Surg 33: 180-186

Meijer M, Van Weeren P, Pijkenhuizen A 2000: Clinical experiences of treating septic arthritis in the equine by repeated joint lavage: a series of 39 cases. J Am Vet Med Assoc 47: 351-365

Moore RD, Lietman PS, Smith CR 1987: Clinical response to aminoglycoside therapy: importance of the ratio of peak concentration to minimal inhibitory concentration. J Infect Dis 155: 93-99

Morton AJ 2005: Diagnosis and treatment of septic arthritis. Vet Clin North Am Equine Pract 21: 627-649

Motta RG, Martins LSA, Motta IG, Guerra C LdePaula, Bolanos CAD, da Silva RC, Ribeiro MG 2017: Multidrug resistant bacteria isolated from septic arthritis in horses. Pesqui Vet Brasil 37: 325-330 
Nix DE, Goodwin SD, Peloquin CA, Rotella DL, Schentag JJ 1991: Antibiotic Tissue Penetration and its Relevance; Models of Tissue Penetration and Their Meaning. Antimicrob Agents Chemother 35: 1947-1952

Oliveira JP, Cipullo JP, Burdmann EA 2006: Nefrotoxicidade dos aminoglicosídeos. Braz J Cardiovasc Surg 21: 444-452

Rubio-Martinez LM, Cruz AM 2006: Antimicrobial regional limb perfusion in horses. J Am Vet Med Assoc 228: 706-712

Santschi E, Adams S. Murphey E 1998: How to perform equine intravenous digital perfusion. 44th Annu Conv Am Equine Pr 44: 1298-1201

Scheuch BC, Hoogmoed LM, Wilson WD, Snyder JR, MacDonald MH, Watson ZE, Steffey, EP 2002: Comparison of intraosseous or intravenous infusion for delivery of amikacin sulfate to the tibiotarsal joint of horses. Am J Vet Res 63: 374-380

Schnabel LV 2012: Pharmacokinetics and distribution of minocycline in mature horses after oral administration of multiple doses and comparison with minimum inhibitory concentrations. Equine Vet J 22: 453-458

Skopnik H, Wallraf R, Nies B, Troster K, Heimann G 1992: Pharmacokinetics and antibacterial activity of daily gentamicin. Arch Dis Child 67: 57-61

Snyder JR, Pascoe JR, Hirsh DC 1987: Antimicrobial susceptibility of microorganisms isolated from equine orthopedic patients. Vet Surg 16: 197-201

Spinosa HS 2006: Farmacologia Aplicada à Medicina Veterinária 4 Edição. Editora Guanabara Koogan, Rio de Janeiro, $897 \mathrm{p}$.

Taylor AH, Mair TS, Smith LJ, Perkins JD 2010: Bacterial culture of septic synovial strutures of horses: does a positive bacterial culture influence prognosis. Equine Vet J 42: 213-218

Thrall MA (Ed.) 2015. Hematologia e Bioquímica Clínica Veterinária. $2^{\text {nd }}$ edn. Roca, São Paulo, 678 p. 